\title{
O exercício da cidadania como instrumento de controle da administração pública
}

\author{
Ariadna Rabelo Angeli - ariadna.angeli@uemg.com \\ Universidade do Estado de Minas Gerais - UEMG
}

\begin{abstract}
Resumo
O exercício da cidadania como instrumento de controle da Administração Pública ocupa o lugar de poderosas armas contra a irresponsabilidade e os abusos do poder administrativo na esfera pública, contudo, muitos cidadãos ignoram os reais significados e suas implicações na vida cotidiana. A evolução dos conceitos de participação popular, até o exercício da cidadania como instrumento de controle, são conteúdos que acompanharam as mudanças da sociedade, atingindo a concepção bem mais abrangente e complexa do que as concebidas em outras épocas da história da humanidade. Objetiva também contribuir para a discussão do papel do cidadão na construção da cidadania efetiva, na utilização dos instrumentos hábeis à fiscalização da administração, no intuito de criar políticas públicas, dar eficácia as políticas intervencionistas, estreitar as relações entre Poder Público e a sociedade, através da disseminação da informação entre os cidadãos, para a promoção de administrações públicas participativas e inteligentes.
\end{abstract}

Palavras Chaves: Controle, Participação, Cidadania

\begin{abstract}
The exercise of citizenship and public administration control instrument takes the place of powerful weapons against irresponsibility and abuse of administrative power in the public sphere, however, many people ignore the real meanings and implications in everyday life. The evolution of the concepts of popular participation, to the exercise of citizenship as an instrument of control, are content that accompanied the changes in society, reaching far more comprehensive and complex design than conceived in other epochs of history. It also aims to contribute to the citizen's role of discussion in the construction of effective citizenship, the use of skilled instruments to supervision by the administration in order to create public policies to effectively interventionist policies, closer relations between government and society through the dissemination of information among citizens, to promote participatory and smart government.
\end{abstract}

Key words: Control, Participation, Citizenship. 


\section{Introdução}

A desinformação ou desinteresse do cidadão brasileiro pela política gera irresponsabilidade e abusos por parte da classe gestora. Não operacionalizar os instrumentos de controle da Administração Pública, colocados à disposição do cidadão é uma das razões do referido problema. O intuito é contribuir com a discussão do papel do cidadão no controle da administração através da utilização desses instrumentos, bem como demonstram que, juntos participação popular, exercício da cidadania e utilização desses instrumentos são poderosas armas no zelo pela res pública.

O controle que é inerente à democracia, ao bem-estar coletivo, possibilitou a criação de ferramentas, legislações, aprovando-as e exigindo que vigorem, em busca de transparência e eficiência das atividades administrativas.

O cidadão impôs sua participação primeiramente de uma forma sutil, pois vários projetos de cidadania foram implementados, legislações criadas, em seguida de forma mais agressiva, se mostrando nas ruas, empoderando-se de direitos, reivindicando melhorias e compromissos em favor da coletividade.

O tema tratado é relevante no incentivo à participação popular, ao despertar para a utilização dos instrumentos existentes, não somente as bandeiras e gritos de ordem em manifestações de rua, mas um grande número de possibilidades de atuar no controle da administração. O objetivo geral é identificar, analisar e descrever nos instrumentos de controle colocados à disposição do cidadão e demonstrar que o exercício da cidadania é um instrumento de controle da administração pública. Para que esse objetivo fosse alcançado foram traçados objetivos específicos como conceituar controle e cidadania; buscar formas de utilização de ferramentas de controle; identificar os instrumentos de controle da administração pública; localizar na legislação as possibilidades de atuação do cidadão e possíveis aliados. Para ao final, comprovar que é possível mudar a administração pública através da participação popular, fazer realizar uma gestão participativa e responsável.

A hipótese levantada é que o desconhecimento ou desinformação leva o cidadão a inércia e ao desinteresse pela administração pública, gerando irresponsabilidade administrativa nos gestores.

A metodologia utilizada será a investigação bibliográfica, bem como pesquisa-ação tendo em vista que o pesquisador está inserido no ambiente da pesquisa, quanto aos fins pesquisa explicativa, com abordagem clara, imparcial e objetiva.

Em decorrência do desenvolvimento da consciência cidadã a participação em audiências públicas, prestações de contas públicas, conselhos e ouvidorias e as manifestações populares podem resultar no fortalecimento da cidadania.

A operacionalização de instrumentos de controle das contas públicas deve levar o cidadão a interessar-se mais pela administração, conseqüentemente, obrigar ao gestor público, a atitudes de maior responsabilidade administrativa. O cidadão começa a ter consciência do seu real poder.

O cidadão fortalecido, enquanto consumidor da prestação dos serviços públicos dispõe, atualmente, de meios mais eficazes para a proteção de seus direitos, ampliando o controle sobre os atos governamentais e a possibilidade de proteção ao patrimônio público e à moralidade administrativa.

\section{Revisão Bibliográfica}

\section{Controle e Cidadania}

O vocábulo "controle" não tem origem no latim, a expressão mais próxima é contrarotulus (contra e rota $=$ diminuição de rota), mas sim do francês contrôle, exame, verificação e fiscalização administrativa, comercial, financeira ou jurídica (NUNES, Rodrigues.1994, p. 107).

A atividade de controle é de vital importância em qualquer organização. Na atividade administrativa não seria diferente.

Entende-se como controle: 
Controle é o exame de resultados. Controlar é ter certeza de que todas as operações a toda hora estão sendo realizadas de acordo com o plano adotado com as ordens dadas, e com os princípios estabelecidos. Ele tende a estimular o planejamento, a significar e fortalecer a organização, aumentar a eficiência do comendo e facilitar a coordenação.(Henry FAYOLL, 1890 apud BOTELHO, 2011 )

O controle é a fiscalização ou verificação administrativa que pode e deve ser realizada pelo pela iniciativa popular, ou cidadã.

FABIANA SOARES se refere ao poder comunicativo do povo atuando na criação legislativa, primando pelo princípio da legalidade das condutas. Contra esse princípio, emerge a participação por controle. As leis são o meio pelo qual ao Estado é possível alcançar os fins que o originaram, devendo tornar efetivas a prática do interesse público e a concepção de sua superioridade sobre o privado.

AYRES BRITO considera a participação popular como expressão do poder político e não como expressão de direito público subjetivo. Também afirma que o controle social do poder é a forma de exercício dos direitos de liberdade e de cidadania, expressão de direito subjetivo público e não como expressão de poder político.

PINSKY, J. afirma que a definição de cidadania é extremamente complexa, vez que não se trata de um conceito estanque, mas histórico, o que significa que seu sentido varia no tempo e no espaço; que é muito diferente ser cidadão na Alemanha, nos Estados Unidos ou no Brasil, não apenas pelas regras que definem quem é ou não titular da cidadania, mas pelos direitos e deveres distintos que caracterizam o cidadão de cada um dos Estados-Nacionais contemporâneos.

PINSKY, define cidadão da seguinte forma:

Ser cidadão é ter direito à vida, à liberdade, à propriedade, à igualdade perante a lei: é, em resumo, ter direitos civis. É também participar no destino da sociedade, votar, ser votado, ter direitos políticos. Os direitos civis e políticos não asseguram a democracia sem os direitos sociais, aqueles que garantem a participação do indivíduo na riqueza coletiva: o direito à educação, ao trabalho, ao salário justo, à saúde, a uma velhice tranqüila. Exercer a cidadania plena é ter direitos civis, políticos e sociais. ( PINSKY, 2003.p.09)

A falta de compromisso com o voto fez com que fosse quebrado o elo entre eleitor e eleito. $\mathrm{O}$ eleitor, por entender ser dono do voto, pode vendê-lo ou trocá-lo como deseja, permitindo que o eleito tenha em mãos um cheque em branco, permitindo, ainda, a consolidação da corrupção no Brasil. Trata-se de uma questão cultural, resquício dos períodos políticos passados, mas ainda latente na vida política brasileira.

O cenário político tem mudado, a sociedade tem cobrado mais, cobra a abertura de processo contra parlamentares, submetendo-os ao controle judiciário, à luz dos princípios constitucionais de moralidade e legalidade, a mídia faz questão de mostrar, o cidadão demonstra sua indignação e reivindica. Também as inúmeras manifestações de rua e ocupações para cada situação que contrarie uma expectativa ou altere uma situação colocada. A Mídia mostra as atitudes de irresponsabilidade e pergunta: Cadê o dinheiro que tava Aqui?

O controle completaria um ciclo da administração, para se verificar se o que foi planejado foi bem executado, se há feedback de correção. Portanto, podemos dizer que quem não controla não está administrando bem. Quem planeja, executa e não controla, não está administrando bem, porque não está acolhendo os feedbaks. Vejamos que o controle permite detectar as chamadas síndromes que vão caracterizar as patologias de administração, as falhas, as irregularidades, as ilegalidades, os desvios de finalidades, os desvirtuamentos de objetivos, a corrupção, a fraude etc. são descompassos de planejamento com a execução e levam naturalmente à ineficiência ou ineficácia.(GOMES, 1995, p. 42)

A Constituição Federal é o instrumento que possibilita o equilíbrio de força no exercício do poder e evita as ingerências do controle na direção e execução dos serviços públicos.

A participação do cidadão torna-se simples e acessível quando ele é ouvido. As ouvidorias, que fazem parte da história, ganharam força de representação entre os usuários dos serviços públicos e as instituições prestadoras desses serviços, para a solução de conflitos públicos. São incumbidas de receber, examinar e encaminhar aos órgãos competentes as reclamações e representações, 


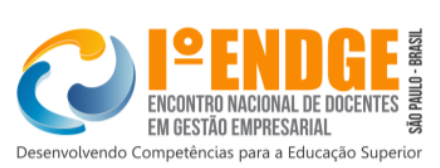

principalmente propor medidas necessárias a regularidades dos trabalhos e ao aperfeiçoamento organizacional, por isso têm sido instituídas junto aos órgãos da administração pública, no papel de ouvidor para realizar o que o cidadão anseia, o que não deixa de ser mais uma forma de controle.

\section{Metodologia}

\section{Formas de Controle Popular}

O Estado Brasileiro consagra as formas mais variadas de exercício da atividade de controle, alguns recepcionados pela Carta Constitucional e nos demais diplomas legais, outros, ainda, pela necessidade em atender aos reclames populares.

O controle pode se manifestar de diversas formas: preventivo, concomitante, sucessivo, corretivo, político e financeiro. Portanto pode anteceder o ato, pode ser realizado juntamente com a realização do ato, pode ser posterior, pode visar correções, pode abranger o mérito da legalidade por natureza política ou financeira quando tenha efeitos sobre o patrimônio.

FERRAZ ( 1999) divide as formas de controle da seguinte forma:

a) quanto ao órgão ou autoridade que o exerce, podendo ser, então, controle parlamentar, controle administrativo e controle judiciário;

b) quanto ao posicionamento dos órgãos controlado e controlador: controle interno e controle externo;

c) quanto ao momento em que se efetiva o controle, podendo ser prévio, concomitante e posterior;

d) quanto à forma de instauração, controle ex officio ou por provocação;

e) quanto à extensão do controle, seja ele controle de legalidade, controle de mérito e controle de resultados.

Seguindo essa divisão, agregando a ela um número ainda maior de formas de controle, o tema foi tratado conforme a divisão que se segue:

\section{Jurisdicional}

2.1 Controle Parlamentar - Direto e Indireto, Controle Administrativo e

O Controle Parlamentar da Administração Pública pode efetivar-se de duas maneiras: direta, quando exercitado motu próprio pelo Poder Legislativo; indiretamente, quando efetivado pelo Legislativo com o auxílio do Tribunal de Contas.

O Texto Constitucional de 1988 atribui: ao Poder Legislativo o controle político dos atos do Poder Executivo, bem como a provocação de agentes políticos para prestarem contas publicamente e informações, pessoalmente, sobre assuntos previamente determinados, importando o não atendimento em crime de responsabilidade, previsto no art. 50 da Constituição Federal, previsão esta que se repete nas Constituições dos Estados e nas Leis Orgânicas dos Municípios. Se o controle é exercido pelos representantes populares, deduz-se que o cidadão pode ser efetivo neste controle.

O controle parlamentar indireto tem previsão no art. 70 da $\mathrm{CF} / 88$, que trata da fiscalização, mediante controle externo e interno de cada poder. Engloba a fiscalização contábil, financeira, orçamentária, patrimonial da administração pública. Neste caso, o Parlamento é o órgão político e o Tribunal de Contas o órgão técnico e auxiliar, no parágrafo único do mesmo artigo em sua redação originária estabelecia-se o dever de prestação de contas, fazia-se menção às pessoas físicas e entidades públicas, silenciando quanto às pessoas jurídicas privadas que tivessem contato com recursos e patrimônio público. Todavia, a EC 19/1988 alterou a redação desse dispositivo, colocando como dever genérico de prestação de contas a toda pessoa física ou entidade pública ou particular que utilize, arrecade, gerencie, administre bens e valores públicos pelos quais responda o Poder Público ou que, em nome deste, assuma obrigação de natureza pecuniária. A falta da pessoa jurídica na letra do artigo, mesmo que fosse óbvio, também estava sujeita ao controle, não era suficiente para afastar as interpretações contrárias. (EMENDA CONSTITUCIONAL 19/1998)

\subsection{Fiscalização Financeira}


Do ponto de vista substancial, a atividade financeira é a busca de meios para satisfação das necessidades públicas, do ponto de vista mais formal, diz respeito a todo o conteúdo financeiro.

Segundo ATALIBA:

o controle financeiro é o conjunto de medidas de natureza fiscalizatória exercida sobre o movimento de dinheiro e bens valiosos, de natureza econômica, manejados por administradores públicos, debaixo da relação de administração. (ATALIBA.1998. p. 78)

Em termos de fiscalização financeira e orçamentária, assume uma importância relevante à figura do ordenador de despesas, de acordo com o Decreto Lei 200/1967, em seu art. 80 que diz: "toda e qualquer autoridade de cujos atos resultem emissão de notas de empenho, autorização de pagamento, suprimento ou dispêndio de recursos da União ou pela qual esta responda." Dispositivo aplicável aos Estados e Municípios.

Todos os benefícios fiscais serão objeto de controle, assim como as subvenções, sua concessão e aplicação, mediante inspeções, auditorias, etc., sempre em conformidade com a Lei 4.320/64.

Fiscalizar o uso das verbas, sejam elas federais, estaduais, e mesmo arrecadação do município, denunciando, exigindo a correção do que está errado é manejar os instrumentos de controle, é cidadania.

Os administradores têm o dever de gastar corretamente e prestar contas, o cidadão tem o direito de saber como o dinheiro público tem sido gasto. Os órgãos criados para fazer a fiscalização financeira não conseguem fazê-lo sozinhos sem a participação do cidadão, acompanhando e controlando a aplicação financeira dos recursos, através dos conselhos responsáveis ou comissões constituídas para este fim.

\subsection{Fiscalização Orçamentária}

O instrumento fundamental na vida diária da administração pública é o orçamento. Coração administrativo e contábil das instituições públicas. Ele é o responsável por definir o modo de funcionamento da máquina financeira e administrativa do Governo Federal, do Estado, do Distrito Federal e dos Municípios.

Trata-se da previsão de receitas e fixação de despesas de um determinado ente por um determinado período. É semelhante à vida privada, ao orçamento de empresas, até mesmo do lar. O que arrecada é receita, o que gasta são as despesas; desnecessário frisar que ninguém pode gastar mais do que arrecada.

FERRAZ cita uma conceituação dada por SOUZA FRANCO que diz:

O orçamento do Estado pode assim ser definido, como a autorização política para cobrar receitas e efetuar despesas durante um certo período, em regra anual, a qual condiciona toda a atividade da Administração no ano financeiro. (FRANCO, 1996. p.295)

A responsabilidade política dos gestores se traduz no dever de pautar-se em critérios de correção, eficácia, economia, honestidade e boa gestão, por isso o Constituinte destinou no Texto Constitucional de 1988 vários dispositivos que demonstram a preocupação com o planejamento da atividade Estatal, dentre eles: arts. 21, IX; 30, VIII; 43, II; 48, II; 49, IX; 68; 74, I; 84, XXIII; 174, caput e $\S 1^{\circ}, 182$.(CONSTITUIÇÃO DA REPÚBLICA FEDERATIVA DO BRASIL DE 1988)

Para tratar cada um dos responsáveis pela execução orçamentária dos entes públicos, faz-se necessário começar pelo Plano Plurianual-PPA que será responsável pela fixação das prioridades de investimentos a médio prazo, que vincularão as despesas de capital a serem consideradas quando da elaboração, a cada ano, da Lei de Diretrizes Orçamentárias-LDO e posteriormente a Leio Orçamentária Anual-LOA.

A LDO antecede a elaboração do orçamento. Ela dirá como o PPA deverá ser executado em uma fração. A LOA será a responsável por autorizar gastos do dinheiro público e pelo cumprimento de cada etapa do plano a que corresponda. Vinculando fontes e dotações orçamentárias. Possibilitando margens de abertura de créditos e remanejamentos desde que autorizados legislativamente. 
Já é previsão que estas leis recebam uma maior participação da sociedade a que serão submetidas, indicando necessidades e votando prioridades.

A Lei Complementar 101/2000, Lei de Responsabilidade Fiscal, artigo 48 trata da transparência da gestão fiscal e assegura no parágrafo único a participação popular, por isso dizer que ela veio completar a exigência por responsabilidade e transparências da gestão pública, estabelecendo como nas empresas privadas o cumprimento de metas e a geração de resultados, sempre com limites pré-fixados. A Lei destinou um capítulo à transparência, controle e fiscalização, definiu vários métodos de verificação da eficácia e eficiência da realização dos objetivos da gestão responsável.

Então, nos municípios, cabe ao cidadão acompanhar de forma efetiva a execução orçamentária, através dos meios de divulgação da administração municipal, tais como o Portal da Transparência(Lei Complementar 131/2009) e das Audiências Públicas Quadrimestrais(Art. $9^{\circ} \S 4^{\circ}$ da LC 101/2000) para apresentação de contas e cumprimento de metas, instrumento trazido pela LRF com o objetivo de envolver a população no processo elaboração e execução orçamentária.

\subsection{Fiscalização Operacional}

A ciência da Administração sugere a retidão de fins e racionalização de meios, através da operacionalização. $\mathrm{O}$ princípio da otimização engloba aspectos relativos à eficiência, eficácia e economicidade das operações administrativas.

Para que haja a fiscalização da efetividade dos métodos utilizados pela Administração na operacionalização dos serviços, para averiguar se os resultados foram atingidos, a Administração tem que se utilizar de auditorias operacionais setoriais, que se diferenciem do controle de legalidade.

O que se quer medir nesta forma de controle é se os fins a que a administração se propôs foram alcançados com eficácia. Nesse caso, o cidadão funciona como medidor da satisfação dos fins propostos pela administração. Efetividade dos programas de governo, a economicidade nos procedimentos, o baixo custo para que os recursos destinados sejam utilizados sem a necessidade de aberturas de créditos especiais ou qualquer forma de remanejamento.

O mecanismo de avaliação desse processo é o cidadão. Todos os procedimentos administrativos visam à satisfação da coletividade, se os métodos utilizados não alcançam os fins a que foram propostos, eles deverão ser revistos. Cabe ao cidadão a denúncia da improdutividade do sistema operacional da administração pública.

\subsection{Fiscalização Patrimonial}

Se tudo que envolve os bens pertencentes à Administração Pública, direta ou indireta, chamamos de patrimônio público, o cidadão é também parte responsável pela guarda deste patrimônio, que se é publico lhe pertence.

Questões relativas à identificação, quantificação, avaliação, revisão, classificação dos bens cuja guarda, conservação, utilização, aplicação, disponibilidade, alienação são confiadas aos agentes públicos ou mesmo particulares em seu nome, cabendo ao cidadão participativo observar o que tem sido feito com a coisa pública, como o gestor tem tratado os bens pertencentes à coletividade.

A fiscalização quanto ao uso e conservação deste patrimônio cabe à administração, mas também a cada cidadão, acionando os meios legais disponíveis, quando percebe que ele está sendo lesado. Um exemplo disso são as denúncias ao Ministério Público, como guardião da coletividade e propositura de Ação Civil Pública (Lei 7.347/85) e as Ações Populares junto ao Poder Judiciário(Lei 4.717/65)

Então, todos os pertences dos órgãos da administração são bens públicos e, portanto, pertencem também aos cidadãos. A ingerência da administração em relação ao seu patrimônio constitui crime.

\subsection{Fiscalização Contábil}

Fiscalização diretamente ligada à Contabilidade, nesse caso com a Contabilidade Pública, ramo de contabilidade geral que orienta, controla e demonstra a organização e execução da Fazenda Pública.

A Contabilidade Pública é responsável por evidenciar a situação de arrecadação de receitas, a forma como se efetuam as despesas e controle dos atos e fatos administrativos sempre relacionados à 
rendas públicas, à demonstração de relatórios e à transparência das contas públicas, bem como as prestações de contas.

A Contabilidade Pública é grande responsável na condução da administração pública ao cumprimento da lei, obediência aos preceitos constitucionais e na disponibilização de dados ao controle interno dos órgãos da administração, ao controle parlamentar e do cidadão. É também a responsável pelo controle interno das contas públicas, servindo de alerta ao gestor público de como vão as contas e o cumprimento das metas estabelecidas pelas normas pertinentes.

Através da publicação periódica de relatórios e demonstrativos da execução orçamentária, e prestação de contas ao TCE, ela dá transparência à gestão, e possibilita o acesso dos cidadãos às contas públicas, garantindo um gerenciamento público.

\section{Análise dos Resultados}

\section{Controle Interno e Externo}

O controle interno é exercido pela própria administração pública, com o objetivo de assegurar a observância do direito e a satisfação das necessidades coletivas, previsto na Constituição Federal artigos 31, 74, 75, Lei de Responsabilidade Fiscal-Lei Complementar 101/2000 artigo 59 e por instruções normativas dos Tribunais de Contas.

A administração Pública pode anular os seus próprios atos, quando eivados de vícios que os tornem ilegais, porque deles não se originam direitos, ou revogá-los por motivo de conveniência ou oportunidade, respeitados os direitos adquiridos e ressalvados em todos os casos a apreciação judicial. (SÚMULA 473 DO STF)

Observa-se que as Administrações Municipais, em especial nos municípios até 30 mil habitantes criam o Controle Interno para cumprir a lei, mas os órgãos não têm efetividade.

Controle Interno exercido diretamente pelo órgão controlador e externo por órgãos auxiliares.

O Controle interno, como o externo, não é estritamente pessoal, mas de natureza funcional. È de importância vital para a Administração e necessária se faz sua definitiva institucionalização, a fim de permitir conhecer resultados que estão sendo obtidos através dos gastos públicos.(MACHADO JUNIOR. REIS. 2004. p. 170)

O controle externo é exercido por diversos órgãos, que não pertencem à estrutura do responsável pelo controlador, como o controle Judiciário e, de forma importante, o controle do Tribunal de Contas, Ministério Público e Controle Social.

Os órgãos de controle externo possuem a responsabilidade de também atender aos pleitos formulados pelo cidadão, quando em observação a administração pública, através de denúncias e questionamentos. O Judiciário, TC e MP quando provocados pelo cidadão, daí o controle social.

\subsection{Tribunal de Contas - TC}

Rui Barbosa foi responsável pela criação do primeiro Tribunal de Contas, através do decreto 966-A, de 7/11/1890. Daí em diante as Constituições passaram a fazer referência ao novo órgão.

Superado o regime autoritário, a Constituição de 1988, consagra o Tribunal de Contas como órgão de controle externo e auxiliar técnico do Poder Legislativo, mas ao mesmo tempo como órgão fiscalizador desse poder, tem reservado um espaço próprio com competência e autoridade para exercer o controle administrativo-financeiro.

Ao TC da União cabem matérias relativas ao modelo Federal, artigo $71 \mathrm{CF} / 88$. O art. 75 $\mathrm{CF} / 88$, consagra a existência do TC dos Estados, do Distrito Federal, vedando a criação de tribunais nos municípios. A vedação contida no artigo 31 da $\mathrm{CF} / 88$, refere-se à criação de órgão, Tribunal ou Conselho de Contas nos municípios, inseridos na estrutura destes. Não proíbe a fiscalização, conhecimento das contas ou controle das mesmas, por parte de todo e qualquer cidadão interessado. 
Nos artigos 31, 71 e $75 \mathrm{CF}$, resguardam a disponibilidade das contas dos Municípios a qualquer contribuinte, para exame e apreciação, podendo questionar-lhe a legitimidade.

O controle exercido pelos TC vai além da análise das contas de cada exercício e a emissão de pareceres, das auditorias requeridas pelos entes, ou por representação, ou denúncias populares, os TC respondem a questionamentos e prestam uma consultoria técnica para que sejam evitadas as rejeições e sanadas as questões duvidosas.

Qualquer cidadão pode se dirigir ao TC para fazer denúncias fundamentadas sobre órgãos da administração pública. O TC é mais um dos instrumentos de controle à disposição para exercícios da cidadania.

\subsection{Ministério Público - MP e Controle Jurisdicional}

A Constituição de 1988 fortaleceu a instituição do Ministério Público atribuindo-lhe a qualificação de órgão essencial à função jurisdicional, para a defesa da ordem jurídica, do regime democrático e dos interesses sociais e individuais indisponíveis(art. 127 da CONSTITUIÇÃO FEDERAL). Como órgão independente, tem reforçado o auxílio ao Poder Legislativo e ao Tribunal de Contas no controle em todos os âmbitos administrativos, controle esse que pode também ser considerado prévio, concomitante ou posterior.

Organismo dotado de autonomia funcional, administrativa e financeira, o MP não chega a ser poder constituído, nem integra o Judiciário, embora atue junto a esse Poder, mas tem reservado para si a função de defensor da sociedade. Ao MP cabe promover ações judiciais: sejam elas penais, civis públicas, ações diretas de inconstitucionalidade, exerce o controle externo da atividade policial, defende diretamente os interesses difusos e coletivos (indígena, idosos, crianças, meio ambiente, consumidor - art.129 CF/88).A Ação Civil Pública ligada constitucionalmente à Ação Popular, ambas visam garantir a defesa de direitos, garantia e interesse violado ou prestes a ser.

O MP figura como o protetor da sociedade, aliado da cidadania quando o seu direito de participação e controle não é respeitado. A permanência da representação em todas as comarcas de um membro representando o MP, tem o condão de mostrar à administração pública que àquele cidadão que desejar participar, acompanhar o desempenho administrativo de seus representantes tem um defensor que pretende resguardar esta participação.

Os casos concretos de interferência do cidadão, diversas são as formas de participação direta do cidadão, ou seja sem mediadores, no cotidiano das administrações, podem ser citadas entre outras:

a) o direito de petição;

b) o direito de se manifestar com liberdade em enquete e pesquisas de opinião;

c) apresentando sugestões em caixas de coleta de sugestões e fale conosco;

d) averiguando através da leitura e acompanhamento de balancetes;

e) a participação em audiências públicas e fóruns que antecedem a elaboração de alguma norma, etc.

Quanto ao Controle Jurisdicional, a participação se dá de forma indireta:

a) participação em órgãos consultivos;

b) representação na Justiça através da Ação Popular, Ação Civil Pública, Mandado de Segurança Individual e Coletivo, demais.

Com o apoio do Poder Judiciário uma importante forma de controle é a exercida pelas entidades organizadas, como associações civis e os conselhos populares, instrumentos de controle dos gastos públicos e da transparência administrativa. Talvez seja a forma de melhor exercer a cidadania do controle, porque evitam os desvios e o mau uso do dinheiro público.

\section{Conclusão}

A participação popular deixou os discursos subversivos e os bastidores da política, isso porque, até pouco tempo a participação era encarada como utopia de classes revolucionárias, mas tornou-se uma realidade, que ganha importância no texto constitucional e fortalece a democracia.

A pesquisa alcançou o objetivo proposto, verificou que durante a evolução da participação cidadã, à atual Carta, denominada como Constituição Cidadã, consolidou as conquistas individuais, sociais, civis e políticas, ampliando no cenário brasileiro o conceito de cidadão. 
Essa consciência fez com que o cidadão deixasse o lugar de coadjuvante ou mero expectador, para ocupar o status de fator principal na história da cidadania e na descoberta dos instrumentos de controle da administração pública.

A hipótese levantada foi confirmada, há uma necessidade latente de conhecer as formas de controle popular disponível, no texto constitucional, na legislação esparsa, demonstrando que estes instrumentos padecem do desconhecimento por parte do cidadão, tornando-o grande responsável pelos abusos das autoridades. O controle administrativo pode ser exercido de diversas formas, como pôde ser observado.

Possível perceber que no intuito de fortalecer o controle popular no Brasil, o constituinte determinou que alguns auxiliares fossem completar o rol de instrumentos postos à disposição do cidadão.

Avaliada a participação popular na utilização dos instrumentos de controle, conclui-se que quanto mais utilizados estes instrumentos, mais democráticas as gestões públicas. Urge, então, a descentralização da administração pública para facilitar o processo participativo, porque o cidadão não figura simplesmente como fiscalizador, mas como parceiro, que conhece as necessidades das comunidades e pode estreitar as relações entre Poder Público e sociedade.

Após pesquisa e abordagem dos instrumentos de controle, ficou constatado que disseminação da informação e a cidadania consciente aliada a utilização dos instrumentos postos à disposição do cidadão podem, sim, controlar as administrações públicas, coibindo os abusos de poder dos gestores e fazendo das administrações mais inteligentes, que administram para o mundo real, ouvindo e traduzindo as necessidades dos cidadãos em busca da satisfação dos administrados.

A cidadania é a origem do poder político do Estado, o controle social é a base dessa organização que deve promover, por excelência, a justiça social, patrocinando uma sociedade aberta e participativa sob os fundamentos da democracia.

O cidadão é o grande responsável por todas as formas controle da administração pública, através do exercício da cidadania, um direito seu, pois igualdade, dignidade e direito de participação jamais lhe serão oferecidos, serão uma conquista contínua e uma descoberta perene.

\section{Referências bibliográficas}

ANDRADE, Nilton de Aquino. Contabilidade pública na gestão municipal. $4^{\text {a }}$ Ed. São Paulo: Atlas 2012.

ARAÚJO, Ângela Maria Carneiro (org.). Trabalho, Cultura e Cidadania: um balanço da história social brasileira. São Paulo: Scritta, 1997.

ATALIBA, Geraldo. República e Constituição. Atualizada por Rosélea Miranda Folgosi. São Paulo: Malheiros, 1998.

BOTELHO, Milton Mendes. Manual Prático de controle interno na administração pública municipal. $2^{a}$ Ed. Curitiba: Jururá, 2011.

BRITO, Carlos Ayres. Distinção entre controle Social do poder e participação popular. Revista de Direito Administrativo, n. 189, jul/set., Rio de Janeiro.1992.

COVRE, Maria de Lourdes Manzini. O que é cidadania. São Paulo: Brasiliense, 1967.

DALLARI. Dalmo de Abreu. Elementos de Teoria Geral do Estado. São Paulo: Saraiva, 2002.

FERRAZ, Luciano. Controle da Administração Pública. Belo Horizonte: Mandamentos, 1999.

FRANCO, Antonio L. de Souza. Finanças públicas e direito financeiro. Coimbra: Almedina.1996.

FRANCO, et. al. História das sociedades: das comunidades primitivas às sociedades medievais. Rio de Janeiro: Ao livro técnico, 1992.

GOMES, Adhemar Bento. Auditoria de gestão governamental. Revista do Tribunal de Contas de Minas Gerais, ano XIV, n. 4, 1996.

LEGISLATIVO. Revistado. Belo Horizonte: ALEMG, n. 32, set. /dez. 2001.

NUNES, Rodrigues. Dicionário Jurídico: Termos em Latim. $3^{\text {a }}$ Ed. São Paulo: Instituto Fênix, 1994. 
SOARES, Fabiana de Menezes. Direito Administrativo de Participação: Cidadania, Direito Estado e Município. Belo Horizonte: Del Rey, 1997.

PINSKY, Jaime; PINSKY, Carla Bassanezi. História da Cidadania. São Paulo: Contexto, 2003.

SPITZCOVSKY, et al. VADE MECUM Constitucional e Adminitrativo. coordenação Darlan Barroso, Marco Antonio de Araújo Junior. $7^{\mathrm{a}}$ Ed. São Paulo: Editor Revista dos Tribunais. 2015.

VIEIRA, Liszt. Cidadania e Globalização. Rio de Janeiro: Editora Record, 1997. 